\title{
A VALORIZAÇÃO DOS PROFISSIONAIS DA EDUCAÇÃO BÁSICA NO CONTEXTO DAS RELAÇÕES FEDERATIVAS BRASILEIRAS
}

\author{
MARIa DilnÉIa Espíndola Fernandes*
}

\begin{abstract}
RESUMO: Verifica-se, por meio de instrumentos jurídico-legais, a valorização dos profissionais da educação básica diante da implantação do Fundeb e do Piso Salarial Profissional Nacional (PSPN) no contexto das relações federativas brasileiras. Procedeu-se à pesquisa documental e revisou-se a literatura concernente. Constata-se que, no âmbito das relações federativas brasileiras, as políticas educacionais poderiam contribuir para o desenho da coordenação federativa, à medida que tais políticas poderiam expressar, por um lado, indícios de colaboração federativa no que tange à redução das desigualdades sociais. Por outro lado, o exercício do poder local ainda se apresenta, muitas vezes, como empecilho à coordenação federativa por meio da política educacional, o que determinaria o forte poder indutor da União frente, entre outras situações, à implantação do PSPN.
\end{abstract}

Palavras-chave: Política educacional. Relações federativas brasileiras. Fundeb. Piso Salarial Profissional Nacional.

\section{THE APPRECIATION OF BASIC EDUCATION PROFESSIONALS WITHIN THE CONTEXT OF BRAZILIAN FEDERATIVE RELATIONS}

\begin{abstract}
By means of legal instruments, the value attributed to (or the appreciation of) basic education professionals is analyzed in face of the implementation of the Fundeb and the National Professional Wage Floor (NPWF) within the context of Brazilian federative relations. The research was based on documents and the relevant literature. Within Brazilian federative relations, the educational policies could contribute to the design of the federal coordination as such policies could express, on the one hand, signs of federal collaboration regarding the reduction of social inequalities. On the other hand, the exercise of local power still represents a hindrance to federal coordination due to the educational policy, which would determine the strong inductor power of the Union, among other situations, regarding the deployment of the NPWF.
\end{abstract}

Key words: Educational policy. Brazilian federative relations. Fundeb. National Professional Wage Floor.

Programa de Pós-Graduação em Educação da Universidade Federal do Mato Grosso do Sul (UFMS). Campo Grande (MS) - Brasil.

Contato com a autora:<mdilneia@uol.com.br>. 
A valorização dos profissionais da educação básica no contexto das relações federativas...

\title{
LA VALORISATION DES PROFESSIONELS DE L'ÉDUCATION DE BASE
} DANS LE CONTEXTE DES RELATIONS FÉDÉRATIVES BRÉSILIENNES

\begin{abstract}
RÉSUMÉ: On constate à travers les instruments juridiques et légaux, la valorisation des professionnels de l'éducation de base en face à l'implantation du Fundeb et du Piso Salarial Profissional Nacional (PSPN) dans le contexte des relations fédératives brésiliennes. On a utilisé la recherche documentaire et la littérature concernante. On constate que dans le cadre des relations fédératives brésiliennes, les politiques scolaires pourraient contribuer à la conception de la coordination fédérative, au fur et à mesure que telles politiques pourraient exprimer, d'une part, des indices de collaboration fédératives en ce qui concerne la réduction des inégalités sociales. D'autre part, l'exercice du pouvoir local souvent apparaît comme un obstacle à la coordination fédérative à travers la politique scolaire, ce qui permettrait de déterminer le fort pouvoir inducteur de l'Etat-nation face, entre autres situations, à l'implantation du PSPN.
\end{abstract}

Mots-clés: Politique scolaire. Relations fédératives brésiliennes. Fundeb. Étage Salarial Professionnel National.

\section{Introdução}

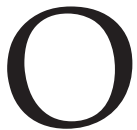

trabalho discute a valorização dos profissionais da educação básica proposta por meio de instrumentos jurídico-legais induzidos pela União, no contexto das relações federativas brasileiras, a saber: o Fundo de Manutenção e Desenvolvimento da Educação Básica e de Valorização dos Profissionais da Educação (Fundeb), que foi instituído por meio da Emenda Constitucional n. 53/2006, regulamentado pela Lei n. 11.494/2007, e a Lei n. 11.738/2008, que instituiu o Piso Salarial Profissional Nacional (PSPN) (BRASIL, 2006, 2007, 2008a).

De fato, ao se retomar a questão da valorização dos profissionais da educação básica no período mais recente, esta se tornou um dispositivo legal à medida que a promulgação da Constituição Federal de 1988 (BRASIL, 1988) - cujo texto expressou a complexa correlação de forças sociais no âmbito do processo de redemocratização do país - instituiu, em seu artigo 206, inciso V, como princípio educacional, a garantia, na forma da lei, de planos de carreira para o magistério público e piso salarial profissional, bem como o ingresso na carreira exclusivamente por concurso público de provas e títulos.

Diante disso, a legislação infraconstitucional - Lei n. 9.394/1996 (BRASIL, 2001), em seu artigo 67, reafirmou o princípio constitucional sobre a valorização dos profissionais da educação, delegando-a aos sistemas de ensino, e dispôs como imperativo para tal fim a realização de concursos públicos, aperfeiçoamento continuado com direito à licença remunerada, planos de cargos e carreira, condições adequadas ao trabalho e piso salarial profissional. 
Os recursos financeiros disponíveis para a valorização dos profissionais da educação seriam aqueles da vinculação constitucional, dispostos no artigo 212 da Constituição Federal e que foram reafirmados no artigo 69, da Lei n. 9.394/1996 (BRASIL, 1988, 2001), quais sejam: recursos resultantes da receita de impostos da ordem de $18 \%$ para a União e $25 \%$ para os estados, Distrito Federal e municípios, no mínimo por ano, para serem aplicados em manutenção e desenvolvimento do ensino (MDE).

Contudo, como argumenta Vieira:

[...] a vinculação não resolve diferenças regionais: por um lado, pelas desigualdades econômicas que todos conhecemos; por outro, pelas características resultantes da descentralização da educação básica. Em outras palavras: $25 \%$ de um estado pobre é infinitamente menor que o mesmo 25\% de um estado ou município rico. (VIEIRA, 2010, p. 44)

As políticas de fundos implementadas a partir de 1998 - Fundo de Manutenção e Desenvolvimento do Ensino Fundamental e de Valorização do Magistério (Fundef) e Fundeb, respectivamente regulamentados pelas Leis n. 9.424/1996 e n. 11.494/2007 (BRASIL, 2001, 2007), - instituíram a subvinculação de recursos e, destes, reservaram $60 \%$ para os salários dos profissionais da educação. Importante destacar que estes recursos para salários no Fundef estiveram estritamente reservados aos professores do ensino fundamental e, no Fundeb, se estenderam aos profissionais da educação básica, em efetivo exercício do magistério. Com efeito, a Lei n. 11.494/2007 dispõe em seu artigo 22 que: “Pelo menos 60\% (sessenta por cento) dos recursos anuais totais dos Fundos serão destinados ao pagamento da remuneração dos profissionais do magistério da educação básica em efetivo exercício na rede pública" (BRASIL, 2007).

Assim, diante das normatizações jurídico-legais sobressai-se, no âmbito das relações federativas brasileiras, a delegação que tal legislação faz aos sistemas de ensino, quando a questão é a valorização dos profissionais da educação por meio de pagamento em espécie. Primeiro porque tal delegação remete à autonomia das unidades subnacionais diante do modelo federativo historicamente construído e de um sistema educacional fortemente descentralizado. De fato, à medida que cada ente federativo pode, legal e legitimamente, constituir seu sistema de ensino (BRASIL, 2001), é ele mesmo o responsável pelo quadro de profissionais da educação para dar curso, manter e aprimorar o seu sistema. Isto posto, significa também que as unidades subnacionais devem instituir, por meio de lei específica, Planos de Cargos, Carreira e Remuneração (PCCR) docentes, de acordo com a legislação federal. Segundo, é cada uma das unidades federativas que detém, a suas expensas de impostos, os recursos financeiros para financiar MDE enquanto receita, de cuja conta se paga os salários dos profissionais da educação básica na forma de despesa. A 
A valorização dos profissionais da educação básica no contexto das relações federativas...

exceção ${ }^{1}$ é recente e se configurou em tempos de políticas de fundos: como a conta do fundo é de natureza estadual, naqueles estados e nos municípios sob sua jurisdição, cuja receita de impostos é insuficiente para alcançar o valor do custo aluno/ano mínimo, a funções supletiva, complementar e redistributiva da União entrariam como equalizador desta condição (BRASIL, 2001, 2007).

Neste contexto, ao se considerar o modelo do Estado federativo, quando a “especificidade do Estado federal, em termos de distribuição territorial do poder, é o compartilhamento da soberania entre o governo central - chamado de União ou governo federal - e os governos subnacionais" (ABRUCIO, 2006, p. 92), interessa aqui verificar nesta dinâmica o comportamento que levaria ao "principio da soberania compartilhada [que] deve garantir o autonomia dos governos e a interdependência entre eles" (ibid., p. 92), no trato das políticas educacionais, ao se considerar a valorização do professor no contexto do Fundeb, pois tal fundo poderia representar a perspectiva de

[...] manter o controle mútuo e a negociação como bases da Federação, [cuja] chave está nas relações intergovernamentais, vinculadas a um equilíbrio entre competição e cooperação. Trata-se do problema da coordenação federativa, aspecto fundamental do federalismo e do processo de descentralização dentro dele. (Ibid., p. 93)

De fato, a aprovação da Lei n. 11.738/2008 (BRASIL, 2008a), que institui o PSPN dos profissionais da educação básica, problematiza especificidades, princípios e coordenações federativas historicamente construídas em solo nacional. Destacar tal Lei é importante porque ela é aprovada no contexto de execução do Fundeb, cujo fundo, ao reordenar os percentuais de impostos vinculados constitucionalmente para financiar MDE, ampliou estes recursos em forma de redistribuição em cada um dos fundos. Contudo, não houve ampliação dos percentuais de recursos vinculados, embora tenha havido consistente elevação na arrecadação dos impostos constitutivos da cesta de receitas do Fundeb; ainda assim, são os recursos que resultam do artigo 212 da Constituição Federal (BRASIL, 1988).

Entretanto, sabe-se que o processo de indução da União no contexto de relações federativas expressa também instrumentos no sentido de equalizar "heterogeneidades [...]. Elas podem ser [...] socioeconômicas (desigualdades regionais), culturais e políticas (diferenças no processo de formação das elites dentro de um país e/ou uma forte rivalidade entres elas" (ABRUCIO, 2010, p. 41). Com efeito, nas condições do caso brasileiro, segundo Abrucio (op. cit., p. 44), “o problema que permaneceu importante, embora já sendo contestado nos estados e cidades maiores, foi o baixo grau de democratização e republicanização no plano local".

Nesse sentido, a implantação do PSPN nas diversas unidades subnacionais, no contexto do Fundeb, tem demonstrado quão difícil tem sido a superação local 
dos tradicionais traços elencados por Abrucio $(2006,2010)$ na construção histórica do federalismo brasileiro.

\section{A valorização dos profissionais da educação básica: entre a indução da União e a polêmica local}

No trato das relações federativas brasileiras, Abrucio (2002, p. 108) aponta que "foi com base em seu poder nos estados que os governadores conseguiram atuar de forma decisiva no plano nacional, exercendo em determinados assuntos forte influência sobre os deputados federais no Congresso Nacional". Vieira (2010) corrobora tal assertiva, quando demonstra em processo histórico posições da esfera parlamentar sobre o tratamento da matéria acerca do piso salarial nacional dos professores, pois "é evidente que a resistência dos governos foi o que falou mais alto e a intencionalidade nunca foi materializada" (p. 36) sobre a questão, ainda em 1989.

Diante disso, a aprovação da Lei n. 11.738/2008 (BRASIL, 2008a) expressou, no âmbito jurídico-legal, por parte da União, a afirmação de um acordo entre parte das reivindicações requeridas pelos trabalhadores em educação ao longo da história, mas que somente a partir dos anos de 1990 começou a ser pautado de forma mais incisiva, pois

[...] o atendimento à previsão constitucional de instituição de um piso salarial nacional para o magistério [...] era reforçado pelo acordo feito por ocasião da Conferência Nacional de Educação, de 1993, que aprovou o Plano Decenal de Educação. Nessa ocasião, o Ministério da Educação e a Confederação Nacional dos Trabalhadores em Educação (CNTE) haviam acordado com o estabelecimento de um piso salarial nacional para o magistério de R\$300,00. (OLIVEIRA; SOUZA, 2010, p. 24)

O acordo de que falam Oliveira e Souza (2010) foi rompido em 1995, quando Fernando Henrique Cardoso assumiu o governo (FERNANDES; RODRIGUEZ, 2011). No lugar, praticou-se o valor do custo aluno/ano mínimo instituído pelo Fundef (ibid., p. 10). Não obstante o Fundef ter instituído a obrigatoriedade de Planos de Cargos, Carreira e Remuneração (PCCR) para o magistério, delegou-se tal prerrogativa às unidades subnacionais.

Por isso mesmo, Gatti e Barreto (2009) irão constatar que, até o final dos anos de 1990, a maioria dos municípios e, também, alguns estados da Federação não tinham ainda construído processos que regulassem a carreira do magistério; estes só passaram a ser elaborados pelos entes federativos, por exigência da implantação do Fundef.

De fato, a aprovação da Lei n. 11.738/2008 (BRASIL, 2008a) materializou, por parte da União, a indução a que estados e municípios assumissem de forma obrigatória um PSPN para os docentes da educação básica que, necessariamente, teria de 
A valorização dos profissionais da educação básica no contexto das relações federativas...

ser articulado com os PCCRs. Diante disso, a possibilidade orçamentária do PSPN está diretamente vinculada ao Fundeb. Neste sentido, o

[...] valor do PSPN foi fixado em $\mathrm{R} \$ 950,00$, sendo este fixado como o valor abaixo do qual os diferentes entes federados não poderiam estipular o vencimento inicial das carreiras do magistério público da educação básica com formação em nível médio na modalidade normal [...], com carga semanal de 40 horas de trabalho, podendo compreender as vantagens pecuniárias já existentes. A partir de 2009, tal piso deverá ser atualizado anualmente no mesmo percentual estabelecido pelo Fundeb para o valor aluno/ano das séries iniciais do ensino fundamental, a ser reajustado de acordo com o INPC/IBGE. (CAMARGO et al., 2009, p. 345)

Simultaneamente, a Confederação Nacional dos Trabalhadores em Educação (CNTE) também lembrou que:

De Acordo com o art. 5 da lei n. 11.738, de 16 de julho de 2008, que instituiu o piso salarial nacional do magistério da educação básica, a correção do piso deve pautar-se pelo mesmo percentual de reajuste do valor mínimo nacional do Fundeb. Assim, o valor de R $\$ 950,00$, definido para 2008, passa a ser de $\mathrm{R} \$ 1.132,40$ em 2009. É preciso destacar que o Projeto de Lei n. 3.776/08, que visa instituir o INPC/IBGE como índice de reajuste do piso, ainda não foi concluído na Câmara e também deverá tramitar no Senado. (CNTE, 2009, p. 1)

Dessa forma, a questão central que se coloca para o pagamento do PSPN aos profissionais da educação básica está diretamente vinculada ao mínimo de $60 \%$ dos recursos destinados ao pagamento de salários, que tem origem na receita de impostos para MDE, conforme disposto no Fundeb.

Cabe lembrar que a Lei n. 11.738/2008 também institui “2/3 (dois terços) de jornada de trabalho docente para o desempenho das atividades de interação com os educandos" (BRASIL, 2008a), situação que provoca impacto no quantitativo de professores e, por isso mesmo, nas finanças públicas, porque altera as relações entre o trabalho docente e sua regulação pelo Estado, com vistas a mudanças por meio de processos qualitativos.

Foi este o ponto de desacordo de estados e municípios com o governo federal que resultou na Ação Direta de Inconstitucionalidade (ADIn), impetrada pelos governadores dos estados. Tal situação promoveu um embate nas relações federativas, quando governadores entenderam - e este foi um dos pontos de justificativa da ADIn - a quebra de autonomia federativa por parte da União (BRASIL, 2008b) que, grosso modo, pode ser compreendida como a interferência do governo central naquilo que não é de sua alçada. A conjuntura ficou convulsa neste aspecto e exigiu posicionamento do Poder Judiciário, pois, entre as razões para a declaração de inconstitucionalidade da Lei n. 11.738/2008 posta na ADIn n. 4.167, estava a de "incompetência e afronta à autonomia dos entes federados: a afetação dos princípios da especialização de funções e federativo" (BRASIL, 2008b, p. 5). A votação da ADIn 
n. 4.167, pelo Supremo Tribunal Federal, em abril de 2011, selou o fim do embate a favor da União (BRASIL, 2011).

Diante disso, as unidades subnacionais agora estão se havendo - de forma obrigatória, não obstante as resistências - com a elaboração de políticas educacionais com vistas a garantir o PSPN para os professores da educação básica no contexto do Fundeb.

Mesmo diante da aprovação da Lei n. 11.738/2008 (BRASIL, 2008a) e da contenda judicial já resolvida, o cenário nacional apresenta situações muito diversas no trato da questão salarial dos profissionais da educação básica, que se expressam em valores remuneratórios. O que há em comum entre as unidades federadas sobre salários docentes "é o baixo salário do professor [...]. No Brasil, como em boa parte do mundo, o poder público é seu maior empregador e, portanto, a remuneração está intimamente ligada à receita pública per capita e à capacidade de mobilização desta categoria profissional" (PINTO, 2009, p. 59). Diante disso,

Tomando como referência a remuneração mensal média de um professor de $5^{\underline{a}}$ a $8^{\underline{a}}$ série ( $R$ \$ 1.088), que deve possuir curso superior para exercer a profissão, constata-se que o policial civil (cuja exigência é de formação em nível médio) possui remuneração $50 \%$ superior; o economista recebe 3,3 vezes mais; o advogado, 2,6 vezes; o delegado, 5,4 vezes; o médico, 4,4 vezes; e o juiz, o topo da lista, 11,8 vezes. É evidente que o médico ou juiz, para ingressar na carreira, possui maior número de anos de formação do que o necessário para a atividade docente, mas, evidentemente, nada justifica a distância salarial entre estas profissões. (Idem, ibid., p. 54)

O problema que se coloca não está somente na esfera do financiamento, à medida que os recursos disponíveis para o pagamento de salários de professores da educação básica são aqueles originados da receita de impostos, cuja base orçamentária alimenta o Fundeb, e é deste fundo que sai o pagamento de tais salários. Por isso mesmo, é consenso na literatura (CASTRO, 2007; PINTO, 2007; DAVIES, 2008; CAMARGO et al., 2009; FERNANDES; OLIVEIRA, 2011) que, se os fundos não trouxeram recursos novos para $\mathrm{MDE},{ }^{2}$ contudo, promoveram transparência na aplicação destes recursos.

Assim, para financiar MDE, as políticas de fundos operam ainda com duas limitações historicamente construídas: a primeira delas deve-se ao fato de que, "particularmente no caso da educação, o limite inferior é estabelecido pelo percentual mínimo, que se transforma em máximo, definido pela vinculação constitucional de impostos" (PINTO, 2009, p. 60-61). A segunda refere-se ao

Impacto dos gastos com aposentados na folha de pagamento. [...] como a LDB foi omissa na explicitação dos custos com aposentadoria, boa parte dos estados e municípios os contabilizam como despesas com manutenção e desenvolvimento do ensino. Assim, parcela 
A valorização dos profissionais da educação básica no contexto das relações federativas...

significativa dos recursos vinculados ao ensino do País está sendo desviada para gastos previdenciários. (Idem, ibid., p. 57)

Contudo, há ainda outra complexidade que se interpõe no âmbito do financiamento para $\mathrm{MDE}$, associada a estas aqui explicitadas, e que interessa igualmente. Trata-se de como o país equacionaria, em regime de colaboração, políticas de coordenação e cooperação federativa para o tratamento do PSPN no âmbito do Fundeb, como principal política de financiamento para o pagamento de salários dos professores da educação básica.

\title{
Fundeb: uma política de coordenação federativa para a valorização dos profissionais da educação básica?
}

\author{
Martins (2010, p. 505), identifica que:
}

O financiamento da educação num Estado federativo insere-se no que Wildavsky e Pressman [...] denominaram de ação conjunta complexa, que se dá nas situações em que diferentes instituições partilham o poder sobre decisões e ações de forma que cresce a complexidade, na medida em que uma tarefa aparentemente simples pode envolver um labirinto de decisões separadas. Daí a necessidade de coordenação e cooperação federativas e de alinhamento do planejamento nas diferentes esferas; enfim, do pleno funcionamento do regime de colaboração.

De fato, no caso brasileiro, o regime de colaboração instituído pelo artigo 211 da Constituição Federal de 1988 (BRASIL, 1988) ainda se encontra em um horizonte de indefinições, à medida que até então não foi regulamentado. Assim, regulamentá-lo para a educação significaria o enfrentamento de um desafio posto para as relações intergovernamentais no tocante a uma justa distribuição de poder, autoridade, e recursos entre os entes federativos, "garantindo a independência e interpenetração dos governos nacional e subnacionais sem que haja comprometimento de um projeto de desenvolvimento nacional, no qual um dos elementos é a educação" (ARAUJO, 2010, p. 764). Mesmo porque:

[...] o regime de colaboração foi gradualmente sendo esquecido do debate sobre o Fundeb, aparecendo apenas no debate sobre o papel da União no financiamento da educação básica, mas sem que fosse apresentado um substitutivo ao modelo de divisão de responsabilidades vigente no artigo 211 da Constituição Federal. Apenas foi alargada a possibilidade legislativa sobre o regime de colaboração, tornando possível desmembrar os aspectos a serem regulamentados, mas sem data marcada para envio ou aprovação no Congresso. (ARAÚJO, 2011, p. 10)

O alcance de tal propósito, contudo, nos remete à compreensão do modelo federativo brasileiro historicamente construído e de que pacto federativo tem se originado deste modelo. 
Tanto Abrucio (2006) como Cury (2010) afirmam que o Brasil, historicamente, tem convivido com aqueles três tipos gerais de federalismo: o centrípeto, que constrói relações de subordinação no âmbito do Estado federal; o centrífugo, que incentiva relações de larga autonomia dos estados-membros; e o cooperativo, que estabeleceria "laços de colaboração na distribuição de múltiplas competências por meio de atividades planejadas e articuladas entre si, objetivando fins comuns. [...] É o registro jurídico forte da nossa atual constituição" (CURY, 2010, p. 153).

Nesta perspectiva, entre o registro constitucional que garante uma concepção de federalismo e a correlação de forças sociais, Rezende (2010) problematiza no sentido de que também existem contradições e tensões no federalismo fiscal brasileiro, cuja centralidade seria a repartição coordenada de tributos entre as esferas nacionais. Argumenta ainda o autor que:

[...] um regime de financiamento de políticas nacionais voltadas para assegurar a todo o cidadão brasileiro iguais oportunidades de ascensão social deve ser parte importante de um modelo de federalismo fiscal, que inclui três outros componentes: a repartição das competências tributárias; a promoção do ajuste vertical, isto é, o equilíbrio na repartição do bolo tributário entre o governo federal, os estados e os municípios; e a adoção de um regime de equalização fiscal para corrigir os desequilíbrios na repartição dos recursos entre os estados e os municípios. (REZENDE, op. cit., p. 84-85)

Por tudo isso, considera este autor que o modelo do Fundeb apresenta limitações na condução do federalismo fiscal, pois "não é suficiente para garantir a igualdade de acesso de todos os cidadãos a um mesmo padrão de provisão de serviços educacionais, para corrigir [...] as distorções que acarretam ineficiência na gestão do gasto público [...] e para promover a equidade inter-regional“ (ibid., p. 83).

É decorrente desse processo a contraditória e tensa construção histórica do binômio centralização versus descentralização no âmbito da política educacional, quando se transfere as ações de uma esfera federativa para outra, sem a consequente contrapartida de recursos (FERNANDES, 2001; OLIVEIRA; SOUSA, 2010). Não obstante as políticas de fundos tenham, em alguma medida, equacionado transferências de recursos financeiros entre as unidades subnacionais, elas apresentam ainda, como limitações para a coordenação federativa, primeiro que o fundo é estadual e, assim, as transferências de recursos ficam circunscritas entre o estado e seus municípios. Segundo, o valor do custo aluno/ano mínimo definido nacionalmente, que encontra como limite o que pode gerar despesa advinda da receita de impostos vinculados constitucionalmente. Terceiro, o Fundeb adentrou um cenário quando já havia se consolidado um forte processo de municipalização das matrículas do ensino fundamental pelo país afora.

De fato, Arelaro (2005, p. 1042) constatou que: 
A valorização dos profissionais da educação básica no contexto das relações federativas...

[...] os dados apontam um vertiginoso processo de municipalização de todo o ensino fundamental - de 1 ${ }^{\mathrm{a}}$ a $8^{\mathrm{a}}$ série - no Brasil, pois, em 2003, já se constatava que dos 31,13 milhões de alunos matriculados no ensino fundamental público (consideradas as redes de ensino estaduais e municipais), cerca de 57,37\% (17,86 milhões de alunos) estavam matriculados no ensino municipal, contra cerca de 42,62\% (13,27 milhões de alunos) nas redes estaduais.

E sobre os processos descentralizadores que incidem nas políticas educacionais e seus impactos nas finanças públicas, considera ainda a autora:

[...] se os municípios tivessem um mesmo padrão de arrecadação de recursos, de tal maneira que se pudesse constatar alguma "homogeneidade" distributiva, seria fácil discutir e entender o processo radical de "descentralização" das responsabilidades de atendimento das políticas sociais, porém o quadro brasileiro está longe dessa situação de equilíbrio financeiro entre as diferentes esferas públicas, e entre cada uma delas. Assim, do ponto de vista de arrecadação de tributos, cerca de $70 \%$ dos municípios dependem, exclusivamente, do Fundo de Participação dos Municípios - o FPM - para as suas despesas regulares, ou seja, para sua "sobrevivência", e isso traduz que a maioria dos municípios brasileiros não tem autonomia financeira, nem condições de adquiri-la, a menos que adotemos uma reforma tributária radical. Não somos o $2^{\underline{0}}$ pior país, em termos de redistribuição de renda, impunemente! (p. 1044)

Tem-se que estes processos em curso no âmbito das políticas educacionais manifestam também uma concepção de Estado que vem sustentando o modelo de federalismo. No caso brasileiro, esgotado o ciclo do Estado desenvolvimentista que surgiu "autoritário - como único modo de arbitrar e repor as regras de convivência com a heterogeneidade - e industrializante - como única via de lidar com as restrições externas e fazer face à complexidade crescente e irrecusável das demandas internas" (FIORI, 2003, p. 136), consagraram-se espaços para materializações de compromissos que arbitram "uma luta constante - e em decorrência dela são tratados 'igualmente', de forma transitória, os vitoriosos de cada turno. Essa dinâmica dá lugar a uma luta interminável e a uma crônica instabilidade financeira, jurídica e política" (idem, ibid., p. 178).

Nesse contexto, uma política de financiamento para a educação básica como o Fundeb poderia ser compreendida como um "mecanismo institucionalizado de diálogo federativo" (MARTINS, 2010, p. 510), em razão também de dispor de uma "Comissão Intergovernamental de Financiamento para a Educação Básica de Qualidade" (Idem, ibid., p. 511). No entanto, "a primeira qualidade do Fundeb é a de obrigar - mais do que induzir - os estados e respectivos municípios a exercerem a cooperação na oferta do ensino público" (FERNANDES, 2009, p. 28).

Diante disso, este autor argumenta também que: "para se ter mais verbas para a educação, ou se aumenta a arrecadação ou se faz crescer o percentual de vinculação. De qualquer forma, o estado ou município vai ter que 'tirar a sola de seu couro'"' (p. 33). 
De fato, a coordenação federativa no âmbito da política educacional ainda continua em disputa em tempos de Fundeb para o PSPN, pois, embora instituído em 2008, desde então, estados e municípios vêm operando a incorporação de adicionais no cômputo das remunerações para que os salários cheguem ao piso. Em outras palavras, tomam o piso como teto, ou seja, mais uma vez aqui está valendo a equação de que o mínimo se transforma em máximo (PINTO, 2009; FERNANDES; RODRIGUEZ, 2011). Ainda, em março de 2013, a CNTE afirma que não pagam o PSPN oito estados, ${ }^{3} 13$ estados $^{4}$ não cumprem a lei do PSPN na íntegra e somente

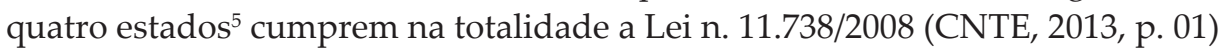

Pontua-se, nesse contexto, a atuação do Conselho Nacional de Secretários de Educação (Consed), ${ }^{6}$ que vem argumentando sobre "a dificuldade de municípios que não têm condições de financiar" o PSPN (CONSED, 2011). Entretanto, a presidenta da União dos Dirigentes Municipais de Educação (Undime) afirmou em entrevista à CNTE:

A Undime sempre foi a favor de um piso nacional de salários para os professores. Então, além de concordar com o pagamento, nós estamos reunindo dados sobre as prefeituras que não têm condições de pagar, o próprio Ministério tem uma proposta de ajuda a esses municípios. E como seria feita essa ajuda? Os municípios têm que provar que não têm condições de pagar. Isso é muito importante porque a gente sabe que os gestores municipais nem sempre são as pessoas que conduzem o orçamento da educação. Então, a transparência no uso dos recursos para que a gente possa ter a clareza daquelas prefeituras que não podem realmente pagar é fundamental para que o MEC possa repassar os recursos. Para fazer esse levantamento, será formado um comitê ou uma comissão que vai analisar cada caso. A Undime vai fazer parte desse comitê, que vai colaborar com o FNDE (Fundo Nacional de Desenvolvimento da Educação) para aprovar ou não a ajuda específica ao município. Será uma análise individual de cada município, feita com os instrumentos de controle que estão regulamentados em lei. Agora, o mais importante é ter a clareza de para onde estão indo esses recursos da educação, se efetivamente as prefeituras não podem pagar ou se há recursos destinados à educação que estão sendo utilizados de maneira não correta. (CNTE, 2011, p. 1).

Observa-se na fala da presidenta da Undime os desafios presentes na conjuntura para que se efetive a bom termo a implantação do PSPN, embora tenha que se considerar que nem sempre as posições defendidas pelos dirigentes das entidades vão representar, de fato, a materialização das políticas educacionais. Antes da construção do consenso, por certo, muitos dissensos hão de ser administrados. A propósito, em 2012, o país contabilizou 2.095.013 professores da educação básica, e 78,1\% deles com formação em nível superior (BRASIL, 2013).

\section{Considerações finais}

Objetivou-se, neste trabalho, verificar a indução da União por meio de instrumentos jurídico-legais com vistas a promover a valorização dos profissionais da educação básica, no contexto das relações federativas brasileiras. 
A valorização dos profissionais da educação básica no contexto das relações federativas...

De fato, a instituição do Fundeb e do PSPN remete à possibilidade de políticas de coordenação federativa, à medida que estabelecem a unidade na diversidade. Sobretudo, porque tais políticas operam com a materialidade disponível para financiar a MDE.

No entanto, para que tais políticas sejam instrumentos de coordenação federativa, terão que se haver com as

[...] inter-relações entre federalismo e patrimonialismo: embora as concepções e modalidades de financiamento da educação sejam estabelecidas em diferentes contextos políticos-governamentais e estejam inseridas no Estado federativo, não se libertaram plenamente das práticas patrimonialistas que permeiam as relações entre os entes federados e entre estes e a sociedade. (MARTINS, 2011, p. 41)

Diante disso, a implantação do Fundeb expressou vínculos de "regras constitucionais, legado de políticas prévias e o ciclo da política [que estrutura] arenas decisórias, [...] fundamental para compreender o sucesso ou o fracasso de dada política pública" (ARAÚJO, 2011, p. 3), mesmo porque, "quando a União formula proposições claras, tem grande capacidade de induzir outros entes federados, mesmo sem investimento de monta" (OLIVEIRA; SOUSA, 2010, p. 23).

Em relação à implantação do PSPN, "uma ideia de quase dois séculos" (VEIRA, 2010, p. 19), também afirmam Fernandes e Rodriguez (2011, p. 89):

Considera-se que a aprovação da Lei n. 11.738/2008 representa um momento histórico de condensação das lutas em torno de melhores condições de trabalho e de remuneração dos trabalhadores em educação do país. Com efeito, trata-se de um processo que remonta ao século XIX e que só se efetivou na primeira década do século XXI, porque só então as condições objetivas e subjetivas se fizeram concretas.

Mesmo assim, a Lei n. 11.738/2008 (BRASIL, 2008a) demonstra que, entre a concepção e sua materialização, vêm tendo relevância significativa as "intrincadas relações federativas brasileiras historicamente construídas” (idem, ibid., p. 98), e permanece ainda em aberto a possibilidade da implantação do PSPN em muitas unidades subnacionais. Têm importância fundamental neste processo que cerceia as políticas de coordenação federativa "os governadores [que] continuam sendo atores estratégicos na definição dos rumos da política nacional e, fundamentalmente, conseguem barrar várias das propostas de alteração do pacto federativo" (ABRUCIO, 2002, p. 170). Associa-se a estes o poder municipal, em que a expressão do localismo se apresenta como frente municipalista, sobretudo, quando está em questão o compartilhamento de competências e responsabilidades entre unidades subnacionais. A propósito, "foi a atuação do Ibam [...] que consolidou a inscrição de um federalismo tridimensional no Texto Constitucional de 1988, representando o ponto de convergência entre o municipalismo e o federalismo, como instituições políticas"' (ARAUJO, 2005, p. 
315), a partir de uma "convergência tecida por equívocos conceituais e históricos que reduziram a democracia à descentralização municipalista" (ibid., p. 315).

Importa registrar que um estudo técnico realizado sobre o "Impacto da Lei do piso salarial dos profissionais do magistério público da educação básica nas finanças municipais" (CNM, 2009) constata que, ao se considerar os "5.563 municípios brasileiros, apenas 2,3\% reuniriam condições para solicitar recursos complementares da União para pagamento do piso, sem considerar um quarto requisito, o da gestão plena dos recursos da educação" (idem, ibid., p. 40). Quando considerado o quesito mencionado, apenas " $0,5 \%$ dos municípios brasileiros estariam dentro dos critérios para receber os recursos federais para complementação do piso" (ibid.). Diante disso, em 2011, a Confederação Nacional de Municípios informou que: "Os recursos do Fundeb não estão sendo suficientes para o pagamento da folha do magistério. Em 2009, 87\% dos municípios comprometeram 75\% do Fundeb com a folha do magistério" (CNM, 2011, p. 08).

De fato, a implantação do PSPN em solo nacional indica que obstáculos históricos construídos em torno das relações federativas se expressam na política educacional de financiamento para MDE. Tais obstáculos complexificam as possibilidades destas políticas serem mecanismos de coordenação e colaboração federativas.

\section{Notas}

1. Exceções anteriores ao Fundef e Fundeb são as escolas técnicas federais e o Colégio Pedro II sob a responsabilidade da União.

2. Com exceção daqueles estados que receberam/recebem complementação da União pelo Fundef e agora Fundeb, em razão de que suas receitas de impostos eram/são insuficientes para chegar ao valor do custo aluno/ano mínimo. Se a complementação da União tem gerado novos recursos para financiar MDE nesses estados, contudo, trata-se de recursos novos para o estado, mas não para a União, à medida que tais recursos despendidos pelo governo federal se originam na vinculação de $18 \%$ que cabe à União para financiar MDE de acordo com o artigo 212 da Constituição Federal de 1988 (BRASIL, 1988). Ademais, Oliveira e Sousa (2010, p. 28) advertem sobre "a limitação dos montantes utilizados pela complementação da União, no caso do Fundef por não cumprimento da legislação, e no caso do Fundeb, por limitação do montante na lei, [que] reduziu o impacto equalizador que as propostas poderiam ter".

3. São os estados de: Alagoas, Amazonas, Bahia, Maranhão, Paraná, Piauí, Rio Grande do Sul e Rondônia.

4. São os estados de: Amapá, Espírito Santo, Goiás, Mato Grosso, Mato Grosso do Sul, Minas Gerais, Pará, Paraíba, Rio Grande do Norte, Roraima, São Paulo, Santa Catarina e Sergipe.

5. Acre, Ceará, Distrito Federal, Pernambuco e Tocantins. A CNTE não dispõe de informação para o estado do Rio de Janeiro.

6. A presidenta atual do Consed - Maria Nilene Badeca - é a secretária de Educação do estado de Mato Grosso do Sul na gestão do governador André Puccinelli, um dos impetrantes da ADIn n. 4.167, que questionou dispositivos da Lei n. 11.738/2008. 
A valorização dos profissionais da educação básica no contexto das relações federativas...

\section{Referências}

ABRUCIO, L.F. Os barões da Federação - os governadores e a redemocratização brasileira. 2. ed. São Paulo: Hucitec, 2002.

ABRUCIO, L.F. Para além da descentralização: os desafios da coordenação federativa no Brasil. In: FLEURY, S. (Org.). Democracia, descentralização e desenvolvimento: Brasil e Espanha. Rio de Janeiro: FGV, 2006. p. 77-125.

ABRUCIO, L.F. A dinâmica federativa da educação brasileira: diagnóstico e propostas de aperfeiçoamento. In: OLIVEIRA, R.P.; SANTANA, W. (Org.). Educação e federalismo no Brasil: combater as desigualdades, garantir a diversidade. Brasília, DF: Unesco, 2010. p. 39-70.

ARAUJO, G.C. Município, Federação e educação: história das instituições e das ideias políticas no Brasil. 2005. 332f. Tese (doutorado em Educação) - Faculdade de Educação da Universidade de São Paulo, São Paulo.

ARAUJO, G.C. Constituição, Federação e propostas para o novo Plano Nacional de Educação: análise das propostas de organização nacional da educação brasileira a partir do regime de colaboração. Educação \& Sociedade, Campinas, v. 31, n. 112, p. 749-768, jul./set. 2010.

ARAÚJO, L. O federalismo brasileiro e a aprovação da Emenda Constitucional n. 53 de 2006. Fineduca - Revista de Financiamento da Educação, v. 1, n. 5, p. 1-13, 2011.

ARELARO, L.R.G. O ensino fundamental no Brasil: avanços, perplexidades e tendências. Educação \& Sociedade, Campinas, v. 26, n. 92, p. 1039-1066, Especial, out. 2005.

BRASIL. Constituição (1988). Constituição da República Federativa do Brasil. Brasília, DF: Senado Federal, 1988.

BRASIL. Câmara dos Deputados. Comissão de Educação, Cultura e Desporto. Coordenação de Publicações. LDB \& Lei do Fundef. Brasília, DF: Câmara dos Deputados, 2001.

BRASIL. Emenda Constitucional n. 53, de 19 de dezembro de 2006. Dá nova redação aos arts. 7º 23, 30, 206, 208, 211 e 212 da Constituição Federal e ao art. 60 do Ato das Disposições Constitucionais Transitórias. Disponível em: <http://www.planalto.gov.br/ ccivil_03/Constituicao/Emendas/Emc/emc53.htm >. Acesso em: 26 ago. 2013.

BRASIL. Lei n. 11.494, de 20 de junho de 2007. Regulamenta o Fundo de Manutenção e Desenvolvimento da Educação Básica e de Valorização dos Profissionais da Educação - Fundeb, de que trata o art. 60 do Ato das Disposições Constitucionais Transitórias; altera a Lei n. 10.195, de 14 de fevereiro de 2001; revoga dispositivos das Leis 
n. 9.424, de 24 de dezembro de 1996, 10.880, de 9 de junho de 2004, e 10.845, de 5 de março de 2004; e dá outras providências. Disponível em: <http://www.planalto.gov. br/ccivil_03/_Ato2007-2010/2007/Lei/L11494.htm>. Acesso em: 26 ago. 2013.

BRASIL. Lei n. 11.738, de 16 de julho de 2008. Regulamenta a alínea "e" do inciso III do caput do art. 60 do Ato das Disposições Constitucionais Transitórias, para instituir o Piso Salarial Profissional Nacional para os profissionais do magistério público da educação básica. Brasília, DF, 2008a. Disponível em: <http://planalto.gov. br/ccivil_03/_Ato2007-2010/2008/Lei/L11738.htm>. Acesso em: 29 mar. 2010.

BRASIL. Supremo Tribunal Federal. Petição Inicial. Ação Direta de Inconstitucionalidade, 28 out. 2008. Brasília, DF: STF, 2008b. Disponível em: <www.stf.jus.br/portal/processo/ verProcessoAndamento.asp? numero $=4167 \&$ classe $=$ ADI\&origem $=$ AP\&recurso $=0 \&$ tipo Julgamento=M>. Acesso em: 3 ago. 2013.

BRASIL. Supremo Tribunal Federal. Certidão de Julgamento Ação Direta de Inconstitucionalidade 4.167, 27 abr. 2011. Brasília, DF: STF, 2011. Disponível em: <http://redir.stf.jus. br/estfvisualizadorpub/jsp/consultarprocessoeletronico/ConsultarProcessoEletronico. jsf?seqobjetoincidente=2645108 >. Acesso em: 21 mai. 2011.

BRASIL. Instituto Nacional de Estudos e Pesquisas Educacionais Anísio Teixeira. Censo da Educação Básica: 2012 - resumo técnico. Brasília, DF: Inep, 2013. Disponível em: <http://download.inep.gov.br/educacao_basica/censo_escolar/resumos_tecnicos/ resumo_tecnico_censo_educacao_basica_2012.pdf >. Acesso em: 12 set. 2013.

CAMARGO, R B. et al. Financiamento da educação e remuneração docente: um começo de conversa em tempos de piso salarial. Revista Brasileira de Política e Administração da Educação, v. 25 n. 2, p. 341-361, maio/ago. 2009.

CASTRO, J.A. Financiamento e gasto público na educação básica no Brasil: 19952005. Educação \& Sociedade, Campinas, v. 28, n. 100, p. 857-876, Especial, out. 2007.

CONFEDERAÇÃO NACIONAL DE MUNICÍPIOS. Impacto da Lei do piso salarial dos profissionais do magistério público da educação básica nas finanças municipais. In: Estudos Técnicos. Brasília, DF: CNM, 2009. v. 2.

CONFEDERAÇÃO NACIONAL DE MUNICÍPIOS. Educação. O piso salarial nacional do magistério público em debate. Informativo CNM, Brasília, DF, 2011.

CONFEDERAÇÃO NACIONAL DOS TRABALHADORES EM EDUCAÇÃO. Notícias. Brasília, DF: CNTE, 2009. Disponível em: <http://www.cnte.org.br/index. php?option=com_content\&task=view\&idItemid=87 >. Acesso em: 27 mai. 2013.

CONFEDERAÇÃO NACIONAL DOS TRABALHADORES EM EDUCAÇÃO. Presidenta da União dos Dirigentes Municipais defende piso do professor. Brasília, 
A valorização dos profissionais da educação básica no contexto das relações federativas...

DF, 19 abr. 2011. Disponível em: <http://www.cnte.org.br/index.php?option=com_ content\&task=view\&id=7523\&Itemid=52 >. Acesso em: 23 mai. 2011.

CONFEDERAÇÃO NACIONAL DOS TRABALHADORES EM EDUCAÇÃO. CNTE divulga tabela atualizada dos estados que não respeitam integralmente a Lei do Piso. 19 de abril de 2013. Brasília, DF: CNTE, 2013. Disponível em: <http://www. cnte.org.br/index.php/lutas-da-cnte/piso-salarial-e-carreira/11802-cnte-divulgatabela-atualizada-dos-estados-que-nao-respeitam-integralmente-a-lei-do-piso.html >. Acesso em: 12 set. 2013.

CONSELHO NACIONAL DE SECRETÁRIOS DE EDUCAÇÃO. Secretário Thiago

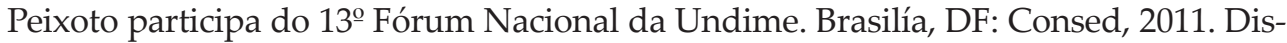
ponível em: <http://www.consed.org.br/index.php/artigos/176-thpeixotoforundime >. Acesso em: 23 maio 2012.

CURY, C.R.J. A questão federativa e a educação escolar. In: OLIVEIRA, R.P.; SANTANA, W. (Org.). Educação e federalismo no Brasil: combater as desigualdades, garantir a diversidade. Brasília, DF: Unesco, 2010. p. 149-168.

DAVIES, N. Fundeb: a redenção da educação básica? Campinas: Autores Associados, 2008.

FERNANDES, F.C. O Fundeb como política pública de financiamento da educação básica. Retratos da Escola, Brasília, DF, v. 3, n. 4, p. 23-38, jan./jun. 2009.

FERNANDES, M.D.E. Políticas públicas de educação: o financiamento da rede estadual de ensino de Mato Grosso do Sul (1991 a 1994). 2001. 250f. Tese (doutorado em Educação) - Faculdade de Educação da Universidade Estadual de Campinas (Unicamp), Campinas.

FERNANDES, M.D.E.; RODRIGUEZ, M.V. O processo de elaboração da Lei n. 11.738/2008 (Lei do Piso Salarial Profissional Nacional para Carreira e Remuneração Docente): trajetória, disputas e tensões. HISTEDBR On-line, n. 41, p. 88-101, mar. 2011.

FERNANDES. M.D.E.; OLIVEIRA, R.C. O Fundef no estado de Mato Grosso do Sul: balanço da política de financiamento para o ensino fundamental (1998 a 2006). Fineduca - Revista de Financiamento da Educação, v. 1, n. 4, p. 1-19, 2011.

FIORI, J.L. O wôo da coruja - para reler o desenvolvimentismo brasileiro. Rio de Janeiro: Record, 2003.

GATTI, B.A.; BARRETO, E.S.S. Professores do Brasil: impasses e desafios. Brasília, DF: Unesco, 2009.

MARTINS, P.S. O financiamento da educação básica como política pública. Revista Brasileira de Política e Administração da Educação, v. 26, n. 3, p. 497-514, set./dez. 2010. 
MARTINS, P.S. Fundeb, federalismo e regime de colaboração. Campinas: Autores Associados; Brasília, DF: UnB, 2011.

OLIVEIRA, R. P. de.; SOUZA, S. Z. Introdução. In: OLIVEIRA, R. P. de.; SANTANA, W. (Orgs.). Educação e federalismo no Brasil: combater as desigualdades, garantir a diversidade. Brasília: UNESCO, 2010. p. 13-35.

PINTO, J.M.R. A política recente de fundos para o financiamento da educação e seus efeitos no pacto federativo. Educação E Sociedade, Campinas, v. 28, n. 100, p. 877-898, Especial, out. 2007.

PINTO, J.M.R. Remuneração adequada do professor: desafio à educação brasileira. Retratos da Escola, Brasília, DF, v. 3, n. 4, p. 51-67, jan./jun. 2009.

REZENDE, F. Federalismo fiscal: em busca de um novo modelo. In: OLIVEIRA, R.P.; SANTANA, W. (Org.). Educação e federalismo no Brasil: combater as desigualdades, garantir a diversidade. Brasília, DF: Unesco, 2010. p. 71-88.

VIEIRA, J.D. Piso Salarial Nacional dos Educadores - dois séculos de atraso. 2. ed. Brasília, DF: CNTE, 2010.

Recebido em 15 de setembro de 2013.

Aprovado em 15 de outubro de 2013. 
